\title{
National Science Policy Looking onto the Next Century - the Case of Sweden
}

\author{
Aant Elzinga and Ants Nuder
}

Forskning-2000 (Research the year 2000) is the title of a new national report reviewing Swedish science policy. The review team presents a sharp critique of several features of Swedish science policy, its structure and the thrust of funding allocation to $R \& D$ during the past couple of decades. Evidence brought forward reveals that there has been a creeping but significant shift, over the years, towards applied fields, at the cost of fundamental curiosity oriented research. The report also criticises semantic confusion concerning terms used to signify different categories that are central to policy discussions, terms such as "R" and "D", "strategic research", etc. which undergird the usual economic householding and accountancy procedures of planning bureaucracies. The conceptual couplet "research-steered" and "contractor-steered" work is introduced, and it is argued that the volume of the latter kind of research has grown out of proportions in comparison and at the cost of the former type. The repport suggests that it is now time to put our house in order by applying corrective action to create a new balance. Among the suggestions several concrete points can be found:

- the call for a stronger focus on and more funding to basic research;

- the need for a reorganisation of the complex funding landscape to create greater homogeneity at this level; in practice a reduction of the number of bodies covering basic and sectoral research by collapsing them into a limited number of new and much larger research council structures that should assume responsibility for the funds now held by four basic research councils and over thirty sectoral funding agencies;

- a recommendation for more funding to technological, natural and medical sciences, and less to the social sciences;

- a proposal to let the much-debated 
strategic research foundations continue with their mandate to stimulate long-term motivated or targeted basic research, although the composition of political representatives on their boards should be changed so as to reflect the power balance amongst parties in the Riksdag, the Swedish parliament;

- a suggestion for the establishment of a new national centre for the study of higher education and research; its purpose would be to provide - on a running basis - policy makers with regular statistics and other data on the performance and organisation of academic and other R\&D-related units activities in the country. The suggestion appears to be coloured by the review committee's own experience, finding difficulty in obtaining accurate information in digestible form on the Swedish science system; and perhaps there is a hidden agenda, to try and perpetuate part of the the committee's own role in another form under the direction of one or another leading higher educational bureaucrat in Stockholm.

The report is presently undergoing scrutiny at the hands of the various stakeholders who may be affected, and it is too early to say if the Riksdag will adopt the main proposals as a basis for a new science policy when looking into the next century. Probably the power of the ministries in charge of the various domains of sectoral funding will not be significantly broken. Similar attempts have been made at various times over the past twenty years, but without success.

More interesting from our point of view is the timing of the report. It comes when Sweden, like many other countries, confronts a situation where decision-making powers over certain events important to the framework conditions for the quality and thrust of research efforts are being shrunk. Loss of power is accompanied by gesticulations that make constant reference to the so called globalisation process, which is frequently portrayed as an irreversible iron law that cannot be faught against. In other words "globalisation" is projected as a reification, which in turn is interpreted as an imperative.

In our estimation the term "globalisation" is a misnomer. The combined process of macro-economic liberalisation, deregulation and privatisation apostrophied is actually the consequence of human actions, particularly ones triggered by stakeholders in financial, banking, and echelons of big business. This proceeds in tandem with an intensification of transnational interconnectivities of a technical nature by virtue of a diffusion of information technologies within geopolitical playing fields. We prefer to refer to the entire process as one of "transnational regional hegemoni-sation"; the reasons for this alternative terminology will become obvious later.

Seen against this background, any attempt to redress the balance of resources, as in the Swedish system, in a direction more favourable for research that may be undertaken independently of direct or indirect signals issuing from "contractor-steering" arrangements, needs to be based on a deeper analysis of global contingencies than what Forskning-2000 has been able to achieve. We agree that a pivotal point in the Swedish system is one of redirecting re- 
search funding on its route to the universities, but contrary to the view of the report, we maintain that the appropriate channel is not merely via the new configuration of research councils, but also - and in equal measure - via significant increases in the block grants that go directly to the university faculties. The faculties need to be put to a test when it comes to their capacity to go up a learning curve as research policy actors in their own right, taking into account the varying demands of a rapidly changing social and techno-economic environment (local, regional, national and global), while keeping intact their own integrity. Under the present conditions it is not certain that the latter criterion is being satisfied.

Our argument for this standpoint is not pinned on any internalist academic egoism, but on a rather sober appraisal of certain overriding economic trends. In many societies today these trends appear to be contributing to a potential levelling of the research landscape, tending to reduce it to a counter-functional handmaiden role vis à vis private commercial enterprise. It is not that we are against university-industrial collaboration per se. What is at stake are the conditions for such collaboration, both those that are in place now, and those which will be perpetuated - albeit in a new form - by the new policy. If the present trend is allowed to continue, (in Sweden) reinforced by a well-meaning half-measure or compromise that does not address the root problems, neither of industry nor of science policy, then we will be hard put in the future. We may find that with the new policy we are actually in the process of shooting ourselves in our own foot.
In the following, against the backdrop of the recent Swedish national review of the science-policy landscape, we want to present a few general pointers. Although they are largely pinned on the realities of the Swedish case, we are convinced that the questions taken up have a wider interest. Many countries, and research communities within them, are facing comparable hard choices. These problems may appear different, varying in country specific terms, but in their structural aspects there are many similarities (for Norway, cf. e.g., Kallerud, 1998).

\section{From the Local to the Global}

Until the end of the previous century it was possible to survive on locally generated knowledge. This was so even if the same knowledge already existed in other parts of the country. With the advent of modern means of transportation, markets in different places started to grow together, and with them locally defined know-how became part of a national entity (Chandler, 1977; Mumford, 1934; Mumford, 1944). Borders between countries also became increasingly permeable as far as knowledge and products were concerned.

At the same time universities as independent repositories of more advanced forms of knowledge began to interact more intensely, and national academies of science started to develop international nodes of non-governmental scientific organisations which later came together under one global umbrella, the present International Union of Scientific Organisations (ICSU) (Greenaway, 1991).

The process leading to an internationalisation of the world has left its mark on 
further developments in the present century (Sundin, 1991). Particularly in the aftermath of the second world war, and even more so with the latest revolution in information technology there has not only been an acceleration (and collaboration) of interconnectivities, but the whole course of development has also been radically altered. Today it is a question of local sites seeking and utilising global knowledge (Gibbons et al., 1994; also Cooper, 1994).

In order to meet increasing globalisation pressures, knowledge of technology, its production as well as potential markets, has become a crucial factor for successful competition. Companies that are active in the global domain have increasingly tended to drift away from associating with particular countries; instead they behave as supranational conglomerates (World Bank, 1997; for implications for science, Gibbons et al., 1994, 111-120). In this context the knowledge that is moved within their own internal organisations moves rapidly without regard to national borders; the knowledge itself is more or less treated like bread or vegetables in the market places, items that need to be fresh and constantly renewed. With this proliferation and rapid transformation of information flows, the ability to select what is relevant and to translate it into applicable knowledge in local sites has become a priority question.

Some of the discussion on the "triple helix" notion concentrates around this question; here there are two different interpretations and concomitant policy lines:

a) neo-corporatist which emphasises plain consensus on activities amongst the representatives of academia, in- dustry and government,

b an evolutionary model, which brings forward and stresses the role of the universities as prime promoters of socioeconomic development (Viale \& Chiglione, 1998).

At the global and national levels respectively the new trends are reflected both in the behaviour of large transnational corporations and in the development of national foresight programmes in a number of countries (cf. Lundvall and Barrás, 1997; the earlier background situation is sketched in Sharp, 1985; implications for IT - Blake, 1992). In each case the purpose is to set priorities and define knowledge profiles.

\section{Anticipatory Intelligence}

A case at hand is L.M. Ericsson. A couple of years ago this company developed its information base mainly through consultants reports and the review of journals and specialist periodical literatures. Today this approach has been replaced by a new mode of serving the company's knowledge needs. Today, some twenty companies specialised in hunting information are engaged. On a daily basis about 4000 new knowledge configurations are automatically structured through the company's intranet (personal communication from Director Gabriel Andersbjörk, Business Intelligence \& Analysis to Ants Nuder). The outcome each day becomes immediately accessible within the entire concern in all parts of the globe. The ultimate value is of course contingent on prior success in defining the search criteria and their degree of precision, as well as the internal structuring of the assembly of incoming information. 
Moreover, it is important that the management of the information process itself is also continually subject to updating to capture the most recent technological opportunities and to be able to apply them in the company's efforts to steadily develop its competitive advantages. Affiliation with university-based centres of competence is an important supplementary hallmark of scientific relevance, quality and credibility, both on the production and sales end.

Intensified international competition puts heavy demands on the conditions of knowledge production and their flexibility. This is the case for industry and universities alike, and also at the level of national policy formation in individual countries. For small countries like Sweden the situation is perhaps more accentuated than in larger countries, and this has a bearing on what the country has to offer in terms of internationally competitive institutions of higher education and research. Domestic environments for research and higher education are put to a test. Past laurels, traditions and old structures only count lightly; environments that do not measure up are forced to become more relevant and efficient. Otherwise the danger is that the country will find it more difficult to participate fully in future developments, while frustration in the long run brings with it a loss of significant competence that will take years to build up anew.

\section{Policies that Can Make a Difference}

At the same time it must be noted that market criteria should not be allowed to decide everything (Slaughter and Leslie, 1997). Otherwise the gaps between groups and institutions with strong re- sources and those that are weak in this respect will become even more acute. If globalisation is allowed to proceed unmitigatedly, production of knowledge that has no direct bearing on productivity and profit maximisation - "added value" as it is now called in the EU context - stands to lose in significance, which will mean great cultural losses. Examples of areas in danger are large parts of the humanities and social sciences (Gibbons et al., 1994, Ch. 4 however points to many new opportunities for the humanities; also see Felt et al., 1995: 149-180). If the argument about globalisation, taking its point of departure from a one-sided fixation on a market-economic perspective, is the main steering factor, the other values and cultural resources represented by the university system will become marginalised. This is something that must be avoided at all costs. Ultimate responsibility rests with regional and national policy formations, and to some degree now with the supranational level represented by the EC (Caracostas, 1998).

Sweden, with its limited resource of human capital produces at the most one percent of the world's new knowledge. This means that a large part of the knowledge that is needed for domestic purposes already exists somewhere else, outside our national boundaries. In addition, it is fair to assume that the major portion of the country's productivity growth also stems from ideas that have their origins elsewhere. This only goes to verify that new knowledge not only builds on familiarity with earlier knowledge but even more so on the capacity to appropriate existing knowledge. For this purpose it is important to maintain critical centres that can provide knowl- 
edge overviews and develop the knowledge base, or core knowledge as we like to call it, and to do so under the auspices of an independent critical mandate. By extension there are also implications for technology assessment procedures, which should be moved in the direction of a participatory mode with dimensions of social shaping and constructivism (cf. Schot, 1998).

Managing and developing bodies of knowledge must therefore be guided by criteria other than those of short-sighted market economic return (cf. Lundvall and Barrás, 1997, Ch. 3, 41-59). This is understood by the more traditional financial dynasties. In Sweden the Wallenberg family, for example, has a Foundation that, on the advice of a select group of science advisers affiliated with it, has an historical track record of strategic investments in $R \& D$-related infrastructures that have borne significant fruit in the long term, both for science and industry (Wallenbergs Stiftelse, 1993). However, it would be foolhardy to leave everything to the good will of more enlightened members of financial echelons. In recent times we see fewer and fewer of these, and an increasing number of speculators. The role of the state as a guardian of basic resources and diversity must therefore be sustained and strengthened if we are to protect vulnerable basic knowledge in the face of market-driven globalisation mechanisms (cf. Callon, 1994). Without a clear policy there is an obvious risk that globalisation will lead to homogenisation and depletion of the country's knowledge base.

\section{Counteracting the MAI and Globalisation Rhetorics}

The risks with the kind of one-sided globalisation pressures noted here has been central in discussions in other countries. It is a curious - and perhaps a telling - fact that the Multilateral Agreement on Investment (MAI), for example, has received so little attention in Sweden. This proposal has in Canada, for example, evoked vocal opposition. This is probably because citizens in that country have plenty of first hand experience with another regime for international investment and trade, NAFTA, on which the MAI is partly patterned. Some critics, like Paul Hellyer, a former minister in Pierre Trudeau's liberal government, have gone as far as calling the proposed agreement, the Multinational corporation's charter of rights and freedoms (Hellyer, 1997: 80). This is not only with regard to new rules for direct investment and capital flow, but also for its ramifications on the freedom of independent inquiry.

In order to meet the pressure of increasing international market demands, a first measure in a country like Sweden is to get a better grasp of the situation regarding global knowledge production and ownership patterns. This means reviewing and compiling the historically produced knowledge that has been published in various domains. In order to be as comprehensive as possible it is appropriate if such knowledge digests are done in different parts of the world simultaneously by a number of researchers independently of each other. Furthermore, there is a need to do continual updates in line with Ericsson's approach via daily scans of the literature, among other via 
the internet. These updating efforts, particularly if the information is to be used in the production of educational material and new knowledge, has to be subject to scientific gatekeeping criteria. This is the case especially when traditional modes of publication that make regular use of peer review procedures are increasingly under pressure, and may be short circuited by virtue of the rapidity of information flows.

Concerning the character of knowledge as a day-to-day fresh item, it is not enough with electronic methods of information gathering. Through personal contacts and face-to-face meetings, conferences, etc. it is important also to remain more directly ajour with what goes on in different research milieus in different parts of the world. Not least it is useful to know what is being planned, and how new research agendas are being forged. The classical Swedish review committee system (utredningsväsendet), building as it does on limited national and international contacts, or individual researchers' windows on current research fronts, is at a disadvantage here. It is no longer sufficient as a basis for decision-making if one wants to meet the future needs of the global demand which in turn is fraught with competitive pressures and short time frames.

Only after the international research front in a given domain has been more comprehensively mapped, it is possible for the research community to more precisely specify the disciplinary directions one ought to prioritise in the light of the ability to compete in an international arena. Thus it is important to emphasise the role of curiosity-driven research, delinked from political and economic forces that seek to orchestrate it. Failing this, and given only top-down attempts to define priorities or "pick winners", important areas of long-term motivated :potential will be lost (cf. Lundvall and Barrás, 1997: 58-59).

\section{Research Training under Pressure}

If the production of new knowledge is to be competitive, it has to be undergirded by qualified education. This is not only a matter of academic education, but also in exceeding measure one of postgraduate training. The latter has to be adapted to international standards and demands. This adaptation should, however, never occur in a manner where critical thinking and depth in education gets marginalised. Nor should industry's short-term problem-solving needs be allowed to compromise the country's need to uphold conditions for maintaining breadth and depth in knowledge production with an eye to the longer term and the various levels of higher education.

Important ingredients in such an internationally oriented research training are the use of the latest in information technology to assist in the critical search and ability to structure older and newer knowledge, secondly, ability to map and assess different research environments, thirdly to identify and select future oriented problem areas, fourthly to use different discipline-specific methodologies, and finally to learn to express oneself verbally and in writing in several languages in order to be able to lead and manage activities in shifting national and international situations and conditions.

Research training when set up in this way may culminate in a proof of appren- 
ticeship in the form of a doctoral exam. The choice of topic may well be transdisciplinary, subordinated to the requirement of demonstrating skills in the art of seeking, formulating and solving problems with the help of scientific methods. Adaptation to the international norm of maximally four years for a $\mathrm{PhD}$ is a given necessity. At the same time it is important in this context that the capacity for critical thinking not be compromised by a reduction of the numbers of hours spent at the postgraduate level. With the impact and development of global knowledge, society's need for general problem solvers has to be taken into account in the current redesign of research training programmes, and dealt with appropriately in the maintenance of internal quality controls at the university. Around the brightest young researchers, those with PhDs with a broad competence, it will be possible for limited periods of time to build up creative environments in areas of significance for the country's long term industrial competitivity. With this, serendipitous search for new knowledge at the post-doctoral level, it is important that choice of topics and orientation of research lines occurs in modes where patented new technologies will not be lost through a one-sided top-down attempt to steer relevant activities.

The overriding purpose for this kind of cutting edge research is to be able to compete for new knowledge in the global market place. As far as Sweden is concerned this means that it is important first and foremost not to increase but rather to try and maintain the country's share of one percent of world scientific production, a figure that tallies well with our part of the collective world fund of human capital.

\section{The Need to Change Incentive Structures}

If the Swedish research community is to be able to participate and compete in the engagement of these bright young researchers, it is also important that the society provides proper economic renumeration, on par with salary levels in other countries. Failing this, these gifted individuals will either be bought up by industry or they will leave the country for continued scholarship at universities in other countries.

Considering the monetary resources of both research councils and strategic foundations in this country, there should not be any shortage of funds when it comes to financing this type of longterm oriented and cutting edge knowledge production (cf. Forskning-2000). On the other hand there is reason to increase attention to and emphasise funding of the broader type of core knowledge that is vital to research training. This may be done either through the channels for allocating funding via bureaucratic state agencies or by rerouting, so that the block grants to the universities are increased. The latter route would involve a redistribution of existing resources in favour of more direct channels to the universities.

It is this latter route we should like to see implemented. What is decisive here, however, seems to be the trust society in the future will place in the university's ability to meet the challenge and identify the problems presented by the steadily changing international demand with regard to capacity building in science and higher education. This is not only a 
question of quality in the choice of research lines and their realisation but even more one of the conditions of employment within academe. A more decentralised mode of funding research also requires a well-grounded science driven policy at the individual universities, one that strategically balances the more serendipitous and broad quest for knowledge driven by internal dynamics of science with the demand for influence from the side of society that manifests itself in different kinds of partnerships with external stakeholders and actors.

The way Sweden will tackle the question of its ability to promote itself in a need for education and new knowledge under the conditions of increasing global competition is one of the great questions that now concerns the country's fate in the next century. This question is all the more significant considering the conservative forces that exist in the research landscape in the form of lifetime appointed administrators and caravans of consultants. In a time when the overriding question is one of radical reconfigurations in the patterns of demand and consumption of knowledge, it is no longer sufficient to secure existing facilities. Indeed, it is important to develop domestic production of education and knowledge services that fit in with international standards and needs, and to do so in a way that will ensure Sweden's future continuation in the front ranks as an attractive alternative and potential partner in the global knowledge market.

\section{Concluding Remarks}

Other countries of similar size face, in principle, the same kind of challenge. Even though they, like Sweden, may have been successful in maintaining a fairly high per capita level of visibility in publication counts and author impact factor assessments using ISI database analysis, the fact remains that such smaller and medium sized countries will never be able to cultivate the more broadly encompassing range of scientific efforts we find in the US, UK or Germany. These are the countries that, together with Canada, figure at the central core of international collaborations according to newest European Science and Technology Indicators Report (European Commission, 1997 EUR 17639); this is so both in terms of co-publications by researchers and in terms of inter-enterprise collaborations in technological alliances, although in the latter instance Germany is moved into a secondary ring and replaced by Japan in the core (670). The technological alliances in turn are concentrated along patterns that replicate the major trading blocks, NAFTA, the EU and the Developing Asian Economies (DEAs) (616). This is fully in line with our notion of a transnational regional hegemonisation, referred to above. Ultimately it is this global context (improperly called globalisation) that the Swedish experience represents problems and possible ways of dealing with them that will have resonance with similarly placed countries. 


\section{References}

Blake, M. (ed.)

1992 The Common Market for Information. London: Taylor Graham.

Callon, M.

1994 "Is Science a Public Good?", Science, Technology and Human Values, vol. 19, no. 4: 395-424.

Chandler, A. D. Jr.

1977 The Visible Hand. The Managerial Revolution in American Business. Cambridge, Ma. : Harvard University Press. Cooper, C. (ed.)

1996 Technology and Innovation in the International Economy. Tokyo: United Nations Press; first publ. 1994.

European Commission

1997 Second European Report on S\&T Indicators. Brussels: DG XII EUR 17639 (December)

Felt, U., Nowotny, H. and Taschwer, K.

1995 Wissenshcaftsforschung. Einführung. Frankfurt/New York: Campus.

Forskning-2000.

1998 (Research the year 2000) Stockholm SOU 1998:128.

Gibbons, M. et al.

1994 The New Production of Knowledge. London: Sage.

Greenaway, F

1991 Science International. A History of the International Council of Scientific Unions. Cambridge: Cambridge University Press.

Hellyer, P.

1997 The Evil Empire. Globalization's Darker Side. Toronto: Chimo Media.

Lundvall, B- $\AA$ and Barrás, S

1997 The Globalizing Economy: Implication for Innovation Policy. Brussels: European Commission, DG XII, Targeted Economic Research - Report EUR 18307.

Mumford L.

1934 Technics and Civilization. London: Martin Secker \& Warburg Ltd.

1944 The Condition of Man. London: Secker \&Warburg Ltd.
Schot, J.

1998 "Constructive Technology Assessment Comes of Age". Pp. 207-231 in Jamison, A. (ed.) Technology Policy Meets the Public. Aalborg: Pesto Papers 2. Aalborg University Press,.

Sharp, M (ed.)

1985 Europe and the New Technologies. London: Francis Pinter.

Slaughter, S. and Leslie, L.

1994 Academic Capitalism. Politics, Policies, and the Entrepreneurial University. Baltimore: The John Hopkins University Press.

Sundin, B.

1991 Den kuperade handen. Människa och tekniken (The Cupped Hand. Humankind and Technology. Stockholm: Carlssons förlag.

Viale, R. and Chizlione, B.

1998 "The Triple Helix Model: a Tool for the Study of European Socio-Economic Systems. Seville: ITPS Report (Nov.).

Wallenbergs Stiftelse

1993 Till landets gagn (For the Good of the Country). Stockholm: Knut och Alice Wallenbergs Stiftelsen).

World Bank

1997 The State in a Changing World. World Development Report 1997. Oxford: University Press.

Aant Elzinga

Department of Theory of Science and

Research

University of Gothenburg

Gothenburg, Sweden

Ants Nuder

Science Advisory Board

Building Research Council

Stockholm, Sweden 